\title{
Healthy People in Healthy Workplace: Philosophy and Practice of Workplace Health Promotion (WHP)
}

\author{
Lucia Isolani and Massimo Cecaro*
}

Occupational Health and Safety Service, ASUR Marche, University of Camerino, Italy

Workplace health promotion (WHP) is the combined efforts of employers, employees and society to improve the health and wellbeing of people at work. This is achieved through a combination of improving the work organisation and working environment; promoting the participation of workers in the whole process of WHP, enabling healthy choices and encouraging personal development [1].

WHP programs are employer-sponsored initiatives directed at improving the health and well-being of workers and often include their families and retirees, and, in some cases, the surrounding local communities where businesses are located.

The workplace is an excellent place to promote health, to the benefit of all society, because it presents an ideal setting: since most working-age adults spend a significant portion of their time at work, the workplace is excellent for building awareness of health and lifestyle issues, introducing and maintaining health promotion programs and providing motivation and support for health improvement, creating workplace environments in which practicing healthy behaviours is "easy" and encouraged by the organization.

Workplace programs can reach large segments of the population that normally would not be exposed to and engaged in organized health improvement efforts and contain a concentrated group of people who usually live in relative proximity to one another and share a common purpose and common culture. In the workplace the communication with workers is relatively straightforward and social and organizational supports are available when employees are attempting to change unhealthy behaviours. Certain policies, procedures and practices can be introduced into the workplace and organizational norms can be established to promote certain behaviours and discourage others. Moreover, financial or other types of incentives can be offered to gain participation in programs. Employers also tend to have longterm relationships with their employees and then the duration of interventions can be longer, making it more probable that employees will attain benefits.

WHP can be combined with existing efforts such as those related to health surveillance, workplace health and safety, and regulatory compliance. Finally, measuring a program's impact can be accomplished by using available administrative data collection methods and analysis systems.

For these reasons, the World Health Organization has developed many sophisticated approaches to health promotion based on education, disease prevention and enhancing fitness in the workplace, based on recognition of the determinants of health and interventions based on a model of how they work together known as the health field concept [2]. The Ottawa Charter (1986) is a key document that brought together WHO's approach and links it with empowerment of the worker, who is encouraged to take responsibility for his or her own health.

Health promotion activities take many forms but generally target exercise and physical activity (sport courses, encouraging physical activity, promoting an active and healthy culture at work), diet (information on healthy nutrition), cancer prevention and health monitoring (checks such as blood pressure or cholesterol level), smoking cessation (free participation in smoking cessation programmes, smoking ban at the whole company site), mental health promotion (anonymous psychological consultancy) and management of chronic diseases through wellness programs.

Health promotion seeks to improve the level of health in a population by preventing diseases, controlling hazards, improving fitness and well being and enhancing the capacity or workers to work and to function in society [3]. By making workers feel better and healthier, workplace health promotion leads to many positive consequences like reduced turnover and absenteeism, enhanced motivation and improved productivity, as well as improving the employer's image as a positive and caring organisation [4].

The evidence supporting the positive effects of WHP has been building over the past 30 years. A systematic literature review commissioned by the U.S. Centers for Disease Control and Prevention (CDC) in 1995 [5], and more recently in 2007 [6] concluded that welldesigned, evidence-based programs built on behavioural theory can achieve long-term health and productivity improvements in worksite populations. Heaney \& Goetzel examined 47 peer-reviewed studies over a 20-years period [7] and found that workplace programs, in spite of their variability in terms of comprehensiveness, intensity, and duration, achieved long-term behaviour change and risk reduction among workers. The most effective programs were those that offered individualized risk-reduction counselling to the highest-risk employees within a "healthy company" workplace environment in which broader health awareness initiatives were already underway.

The review released in 2007 by the CDC Community Guide Task Force examined data from over 50 studies that reported workplace program participation outcomes based on a range of health behaviours, physiologic measures, and productivity indicators. When measured at an individual level, many of the changes in these outcomes were small, but at the population level they were considered substantial [6]. Aside from reducing health risks and improving health promoting behaviours, the task force noted that there may be additional benefits associated with workplace programs,

In conclusion, more attention should be directed at understanding

*Corresponding author: Massimo Cecaro, Occupational Health and Safety Service, ASUR Marche, University of Camerino, Italy, Tel: +300733280159; Fax: +300733280159; E-mail: massimo@cecaro.com

Received July 15, 2013; Accepted July 18, 2013; Published July 19, 2013

Citation: Isolani L, Cecaro M (2013) Healthy People in Healthy Workplace: Philosophy and Practice of Workplace Health Promotion (WHP). J Mass Communicat Journalism 3: e136. doi:10.4172/2165-7912.1000e136

Copyright: (c) 2013 Isolani L, et al. This is an open-access article distributed under the terms of the Creative Commons Attribution License, which permits unrestricted use, distribution, and reproduction in any medium, provided the original author and source are credited. 
Citation: Isolani L, Cecaro M (2013) Healthy People in Healthy Workplace: Philosophy and Practice of Workplace Health Promotion (WHP). J Mass Communicat Journalism 3: e136. doi:10.4172/2165-7912.1000e136

Page 2 of 2

the value of WHP programs in achieving long-term improvements in the health and well-being.

Health care costs continue to rise because the care delivery system favour paying for the treatment of chronic and expensive diseases rather than preventing them in the first place. Thus more attention needs to be directed toward health promotion and disease prevention as part of a comprehensive strategy for improving the health and reducing the social and financial burdens imposed by preventable illnesses.

Thus, healthy workplace are conditio sine qua non for keeping people and, first of all, workers healthy with the aim of containing ballooning health care costs.

\section{References}

1. Woolf SH (2008) The Power of Prevention and What It Requires. Journal of the American Medical Association 299: 2437.

2. Goetzel RZ, Long SR, Ozminkowski RJ, Hawkins K, Wang S, et al. (2004)
Health, Absence, Disability, and Presenteeism Cost Estimates of Certain Physical and Mental Health Conditions Affecting US Employers. Journal of Occupational and Environmental Medicine 46: 398-412.

3. Anderson D, Whitmer R, Goetzel R (2000) The relationship between modifiable health risks and group-level health care expenditures: A group-level analysis of the HERO database. American Journal of Health Promotion 15: 45-52.

4. Goetzel RZ, Jacobson BH, Aldana SG, Vardell K, Yee L (1998) Health Care Costs of Worksite Health Promotion Participants and Non-Participants. Journal of Occupational and Environmental Medicine 40: 341.

5. Wilson MG, Holman PB, Hammock AA (1996) Comprehensive review of the effects of worksite health promotion on health-related outcomes. American Journal of Health Promotion 10: 429-435.

6. Task Force Community Preventive Services. Proceedings of the Task Force Meeting: Worksite Reviews. Atlanta, GA: Centers for Disease Control and Prevention, 2007.

7. Heaney CA, Goetzel RZ (1997) A review of health-related outcomes of multicomponent worksite health promotion programs. American Journal of Health Promotion 11: 290-307. 